\title{
Multiple Voltage-Dependent Mechanisms Potentiate Calcium Channel Activity in Hippocampal Neurons
}

\author{
Ege T. Kavalali and Mark R. Plummer \\ Department of Biological Sciences, Rutgers University, Piscataway, New Jersey 08855-1059
}

Neuronal voltage-gated calcium channels provide a pathway for calcium influx that is required for processes ranging from intracellular signaling to alterations in cellular excitability. In hippocampal neurons, we have characterized a subtype of dihydropyridine-sensitive L-type calcium channels (Lp channel) that shows multiple kinds of voltage-dependent potentiation of its activity. One type of potentiation is elicited by low-voltage stimuli $(-10 \mathrm{mV})$ and can be seen in dual-pulse protocols in which a transient hyperpolarization is interposed between conditioning and test pulses. The second type of potentiation is elicited by much higher voltages $(+60 \mathrm{mV})$ and is selectively deactivated at hyperpolarized voltages. We have compared these types of potentiation in the Lp channel, the "standard" L-type channel, and the cardiac L-type channel. Our results show that the high-voltage potentiation is common to all three channel types. The low-voltage form of potentiation, however, is unique to the Lp channel. Thus, the Lp channel shows two kinds of potentiation that differ in their voltage dependence and rate of decay. Therefore, calcium channel plasticity in the hippocampus has a variety of forms distinguished by their stimulus requirements and duration.

Key words: calcium; calcium channel; hippocampus; potentiation; facilitation; dihydropyridine; plasticity
Voltage-gated calcium channels are essential regulators of neuronal activity. By controlling the flow of extracellular calcium into the cytoplasm, these proteins trigger neurotransmitter release (Augustine et al., 1987), alter action potential firing (Bertolino and Llinas, 1992), and induce gene expression (Morgan and Curran, 1986; Murphy et al., 1991; Bading et al., 1993). As might be expected from this diversity of function, multiple kinds of calcium channels can be distinguished on the basis of pharmacological, structural, and kinetic criteria (for review, see Dunlap et al., 1995). At present, the most reliable pharmacological tools for calcium channel identification are dihydropyridine (DHP) agonists and antagonists and peptide toxins such as $\omega$-conotoxin GVIA, $\omega$-agatoxin IVA, and $\omega$-conotoxin MVIIC (Plummer et al., 1989; Mintz et al., 1992; Sather et al., 1993; Randall and Tsien, 1995). DHP-sensitive calcium channels are the most widely distributed, being found in both neuronal and non-neuronal cell types, whereas toxin-sensitive channels are found predominantly in nerve cells (Dunlap et al., 1995).

Calcium channel activity can be modulated dynamically in various ways. Neurotransmitters, for example, can profoundly decrease the responses of $\mathrm{N}$ - and P-type calcium channels to depolarizing voltage pulses (for review, see Dolphin, 1995). This type of modulation has a powerful impact on neuronal activity and is a fundamental mechanism used by cells to regulate calcium entry (for review, see Anwyl, 1991). One kind of modulation, however, does not depend on application of external compounds-it is

Received Aug. 7, 1995; revised Nov. 21, 1995; accepted Nov. 29, 1995.

This research was supported by grants from the American Heart Association (93-G-53), National Institutes of Health (NS 34061), and Hoechst-Celanese. We thank Drs. S. Aucrbach, R. L. Davis, and E. S. Levine for their helpful discussions and comments on this manuscript.

Courspundence should be addressed to Mark R. Plummer, Department of Biological Sciences, Rutgers University, Nelson Lab, Busch Campus, Piscataway, NJ 08855-1059.

Dr. Kavalal's present address: Department of Molecular and Cellular Physiology, Beckman Center, Stanford University Medical Center, Stanford, CA 94305.

Copyright $\odot 1996$ Society for Neuroscience $0270-6474 / 96 / 161072-11 \$ 05.00 / 0$ elicited by changes in membrane potential. This type of modulation, described as voltage-dependent potentiation, refers to a transient enhancement of channel activity produced by a "conditioning" depolarization. It is associated primarily with DHPsensitive calcium channels and has been found in adrenal chromaffin cells (Fenwick et al., 1982; Hoshi and Smith, 1987; Artalejo et al., 1991a), cardiac myocytes (Pietrobon and Hess, 1990), and skeletal muscle (Sculptoreanu et al., 1993b).

In hippocampal neurons, we have observed a type of calcium channel potentiation that is distinct from that found in non-neural tissue (Kavalali and Plummer, 1994). It can be elicited by relatively low voltages, can survive transient hyperpolarization, and is observed in the presence of DHP agonists. We have suggested that this low-voltage potentiation (LVP) can be attributed to a novel kind of DHP-sensitive calcium channel (Lp channel) that is distinct from the "standard" L-type calcium channel (Ls channel) in hippocampal neurons. The two channel types can be distinguished from one another on the basis of conductance, mean open time, and characteristic gating patterns (Kavalali and Plummer, 1994).

We show that DHP-sensitive calcium channels in hippocampal neurons display two distinct kinds of calcium channel potentiation, which differ in their voltage dependence and duration. One type is a low-voltage form that is unique to Lp calcium channels. The second is a high-voltage form similar to that observed in cardiac L-type channels which is present in both hippocampal Ls and $L p$ channels. The presence of two types of neuronal calcium channel potentiation allows for sophisticated activity-dependent modulation of calcium entry.

\section{MATERIALS AND METHODS}

For single-channel recordings, hippocampal neurons were obtained from embryonic day 18 Sprague-Dawley rats, and cells were plated on Falcon "Primaria" dishes (Sigma, St. Louis, MO) at a final density of $10^{\circ}$ cells/dish. Cultures were prepared according to Lu et al. (1991) and maintained in serum-free medium $(\mathrm{SFM})$ at $37^{\circ} \mathrm{C}$ in a $95 \% \mathrm{O}_{2} / 5 \% \mathrm{CO}_{2}$ 
humidified incubator. SFM consisted of a $1: 1(\mathrm{v} / \mathrm{v})$ mixture of Ham's F-12 and Eagle's minimum essential medium supplemented with insulin (25 $\mu \mathrm{g} / \mathrm{ml})$, transferrin $(100 \mu \mathrm{g} / \mathrm{ml})$, putrescine $(60 \mu \mathrm{M})$, progesterone $(20$ nм), selenium (30 nM), glucose ( $6 \mathrm{mg} / \mathrm{mul}$ ), and penicillin-streptonycin $(0.5 \mathrm{U} / \mathrm{ml}$ and $0.5 \mathrm{mg} / \mathrm{ml}$, respectively). Recordings were performed 3-10 $\mathrm{d}$ after dissociation. All chemicals, unless otherwise specified, were from Sigma.

For whole-cell recordings, an acute dissociation technique was used. This procedure was based on the method described by Johnson and Byerly (1994). Hippocampi from 7- to 16-d-old Sprague-Dawley rats were removed rapidly and cut into 300 - to $400-\mu$ m-thick slices using a McIlwain tissue chopper (Brinkmann Instruments, Westbury, NY). These slices were incubated at $35^{\circ} \mathrm{C}$ in a piperazine- $N, N^{\prime}$-bis(2-ethanesulfonic acid) (PIPES) saline as follows (in $\mathrm{mM}$ ): $120 \mathrm{NaCl}, 5 \mathrm{KCl}, 1 \mathrm{CaCl}_{2}, 1$ $\mathrm{MgCl}_{2}, 20$ PIPES, and 25 glucose, $\mathrm{pH} 7.0$, with added protease $(2 \mathrm{mg} / \mathrm{ml}$ Sigma type XIV, St. Louis, MO) for $10 \mathrm{~min}$ and bubbled continuously with medical grade oxygen. Tissue slices were later rinsed in the PIPES saline without protease and gently triturated into a scintillation vial in which they were constantly stirred in an $\mathrm{O}_{2}$ atmosphere. As needed, hippocampal neurons were triturated onto poly-L-lysine-coated Petri dishes in the PIPES saline without protease. Neurons prepared this way were viable for up to $5 \mathrm{hr}$, and they had few or no processes, making them suitable for voltage clamp. Cell capacitances ranged from 7 to $10 \mathrm{pF}$, Single-channel recordings from theses cells showed that they contained Lp channel activity indistinguishable from that observed in embryonic neurons $(n=15)$.

Cardiac myocytes were prepared from neonatal (4- to 7-d-old) rats with a method adapted from Clapp and Gurney (1991). Animals were euthanized, and the hearts were removed and sliced into $400 \mu \mathrm{m}$ sections with a McIlwain tissue chopper. Slices were placed in an oxygenated, low-calcium dissociation medium as follows (in $\mathrm{mM}$ ): 0.16 $\mathrm{CaCl}_{2}, 110 \mathrm{NaCl}, 5 \mathrm{KCl}, 2 \mathrm{MgCl}_{2}, 10$ HEPES, $10 \mathrm{NaHCO}_{3}, 0.5$ $\mathrm{KH}_{2} \mathrm{PO}_{4}, 0.5 \mathrm{NaH}_{2} \mathrm{PO}_{4}, 10$ glucose, 0.49 EDTA, and 10 taurine, $\mathrm{pH} 7.0$. Cells were stored overnight at $4^{\circ} \mathrm{C}$ in dissociation medium with added papain $(0.5 \mathrm{mg} / \mathrm{ml}$ ) and bovine serum albumin (Sigma Fraction $\mathrm{V}, 2$ $\mathrm{mg} / \mathrm{ml}$ ). The next day, cells were incubated in the enzyme solution with $0.1 \mathrm{~mm}$ dithiothreitol at $37^{\circ} \mathrm{C}$ for $10 \mathrm{~min}$. 'I hey were then rinsed with enzyme-free solution and kept at $4^{\circ} \mathrm{C}$ in dissociation medium until their use. As needed, cells were triturated onto poly-L-lysine-coated Petri dishes in the calcium-free, single-channel recording bath solution (see below). Only relaxed and striated cells were used for recordings. Cells prepared this way remained viable for up to $24 \mathrm{hr}$.

Cell-attached single-channel recordings (Axopatch 200 amplifier, Axon Instruments, Foster City, CA) were made with barium as the charge carrier as follows (in min): $110 \mathrm{BaCl}_{2}, 10 \mathrm{HEPES}, p \mathrm{H} 7.5$. A depolarizing external recording solution was used to bring the potential inside of the cell to $\sim 0 \mathrm{mV}$ as follows (in $\mathrm{mM}$ ): $140 \mathrm{~K}$-gluconate, 10 HEPEStetraethylammonium hydroxide, and 5 EGTA, pH 7.5. In most of the experiments, $0.1 \mu \mathrm{M}$ DHP agonist (+)-(S)-202-791 (gift from Sandoz Co., Basel, Switzerland) was added to the bath solution to clarify the number and types of calcium channels in the patch. Data were sampled at $5 \mathrm{kHz}$ and filtered at I kHz (IDA 15125 interface, Indec Systems, Capitola, CA). Eight-hundred millisecond voltage pulses (typically $160,160,320$, and 160 msec at holding, prepulse, test, and holding potentials, respectively, or $160,160,20,160$, and $300 \mathrm{msec}$ for dual-pulse experiments with interpulse hyperpolarization) were delivered at $5 \mathrm{sec}$ intervals. Linear leak and capacitative currents were subtracted digitally.

Whole-cell recordings were made with barium as the charge carrier as follows (in mM): $20 \mathrm{BaAc}_{2}, 135$ tetraethylammonium chloride, 0.001 tetrodotoxin, and 10 HEPES, pH 7.4. The pipette contained (in $\mathrm{mm}$ ) 108 cesium methanesulfonate, $4 \mathrm{MgCl}_{2}$, 9 EGTA, 9 HEPES, $4 \mathrm{Mg}$-ATP, 14 creatine phosphate, $0.3 \mathrm{Na}_{3} \mathrm{GTP}$, and $50 \mathrm{U} / \mathrm{ml}$ creatine phosphokinase, $\mathrm{pH}$ 7.4. Series resistances were 7-9 $\mathrm{M} \Omega$ before compensation. All experiments were carricd out at room temperature. Data were sampled at 10 $\mathrm{kHz}$ and filtered at $5 \mathrm{kHz}$. Four-hundred millisecond voltage pulses (typically 80,80 , and $240 \mathrm{msec}$ at holding, test, and holding potentials, respectively) were delivered at $4 \mathrm{sec}$ intervals. Leak currents were measured with hyperpolarizing pulses to $1 / 10$ the step potential.

Open times and open probabilities were obtained from sweeps idealized with a half amplitude crossing criterion and cubic spline interpolation (Colquhoun and Sigworth, 1983). Values were plotted on square root-log coordinates, and mean open times were estimated from maximum likelihood fitting (Sigworth and Sine, 1987). Statistical comparisons were made with Student's $t$ test.

\section{RESULTS}

In a previous study (Kavalali and Plummer, 1994), we showed that calcium channel reopenings could be observed at a potential of $-40 \mathrm{mV}$ after voltage pulses from +10 to $+40 \mathrm{mV}$. Because this was not attributable to recovery from inactivation, and because DHP-sensitive calcium channels typically do not open at $-40 \mathrm{mV}$, we concluded that the reopenings were caused by a transient change in channel excitability that promoted activity at a potential that was more negative than usual. We have referred to this change in excitability as voltage-dependent potentiation. In this study, we examined the effects of larger voltage pulses, with magnitudes comparable to those used to elicit calcium channel potentiation in adrenal chromaffin cells (Artalejo et al., 1991a,b), cardiac myocytes (Pietrobon and Hess, 1990), and cloned cardiac L-type channel $\alpha_{1}$ subunits expressed in Chinese hamster ovary cells (Sculptoreanu et al., 1993a). Initially, we used step-pulse protocols (i.e., a two-pulse protocol in which there is no delay between the voltage steps) to study channel activity. Cell-attached single-channel recordings from patches containing $L p$ channels showed that $-20 \mathrm{mV}$ test pulses alone elicited few calcium channel openings (Fig. 1A). If the test pulses were preceded by conditioning prepulses, however, the number of openings at $-20 \mathrm{mV}$ increased dramatically (Fig. $1 B, D)$. Moderate prepulses $(+40$ $\mathrm{mV}$ ) produced a different effect than large $(+120 \mathrm{mV})$ prepulses did. After the $+40 \mathrm{mV}$ prepulse, the number of openings during the test pulse increased, but otherwise the openings were similar in amplitude and duration to those observed when $-20 \mathrm{mV}$ pulses were studied on their own (Fig. $1 B$ ). After $+120 \mathrm{mV}$ prepulses, however, long-duration openings were observed that were never seen in response to the $-20 \mathrm{mV}$ pulse on its own (Fig. 1D). An analysis of open times from several experiments showed that openings at $-20 \mathrm{mV}$ had an additional long component of open time when preceded by a $+120 \mathrm{mV}$ prepulse $(9.3 \mathrm{msec}$; Fig. $1 F)$ as compared with a $+40 \mathrm{mV}$ prepulse (Fig. $1 \mathrm{C}$ ).

For comparison, we also studied patches that contained no $\mathrm{Lp}$ channels. In these experiments, we found that prepulses did not croke additional openings. We did obscrve transitions that produced long-duration tail currents of the type that have been reported previously for cardiac L-type channels (Pietrobon and Hess, 1990). The prolonged tail currents were observed at -20 $\mathrm{mV}$ after prepulses to $+120 \mathrm{mV}$ (Fig. $1 E$ ) but were not seen when $+40 \mathrm{mV}$ prepulses were used (data not shown).

To determine the number of channels in membrane patches, facilitate accurate analysis of data, and ensure reliable identification of DHP-sensitive calcium channels, additional single-channel recordings were made in the presence of $0.1 \mu \mathrm{m}$ DHP agonist (+)-(S)-202-791. This concentration prolonged the open times of DHP-sensitive calcium channels but did not occlude voltagedependent potentiation. In some experiments, we used a higher concentration of agonist $(0.5 \mu \mathrm{M})$, but the results obtained were identical to those seen with the lower concentration. Responses of three different kinds of calcium channels were examined: Ls and Lp channels from hippocampal neurons and also the L-type calcium channel from cardiac myocytes (Lc channel). The test pulse was $-30 \mathrm{mV}$ and was either used alone or immediately preceded by conditioning prepulses of varying amplitude.

Cell-attached single-channel recordings from patches containing either a single Lp, Ls, or Lc channel showed that test pulses to $-30 \mathrm{mV}$ elicited essentially no channel activity on their own (Fig. $2 A-C$, left traces). When these test pulses were preceded by conditioning prepulses, calcium channel activity was potentiated. 
A
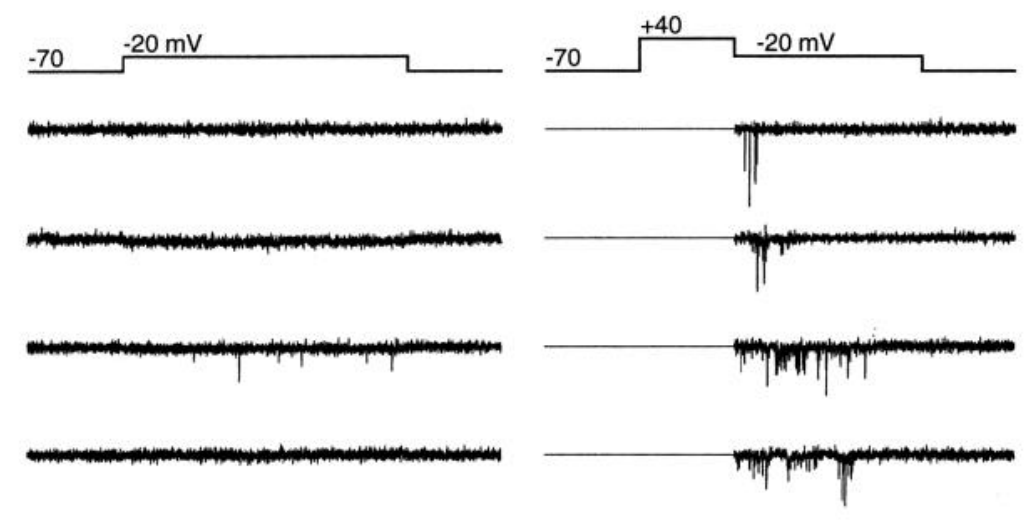

D

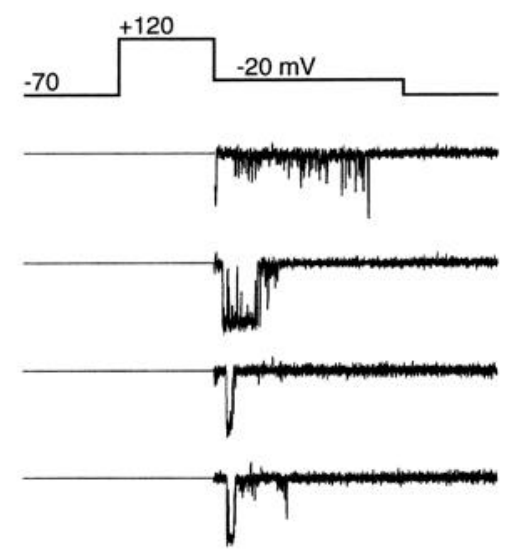

B

E

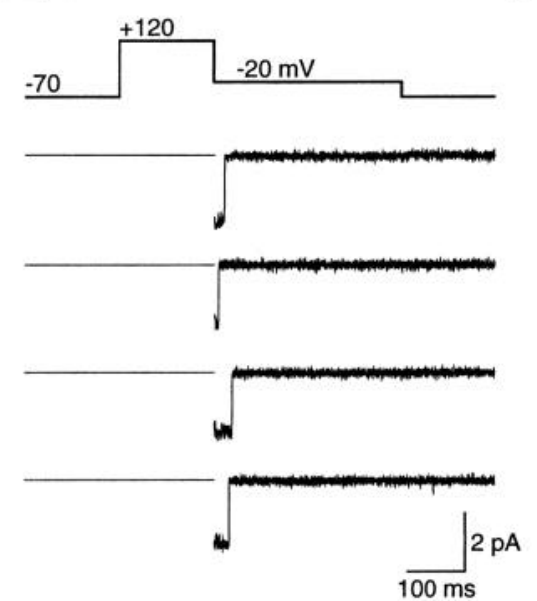

C

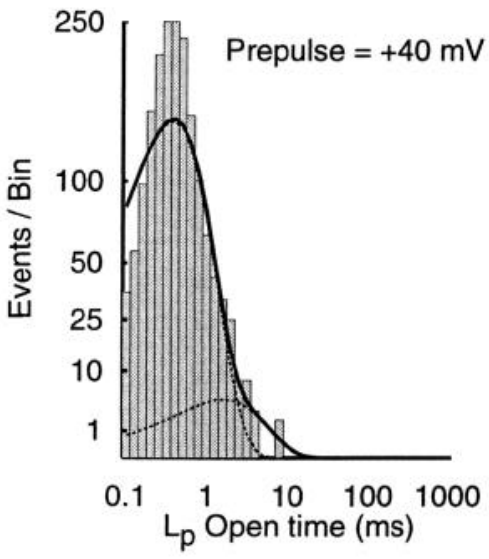

F

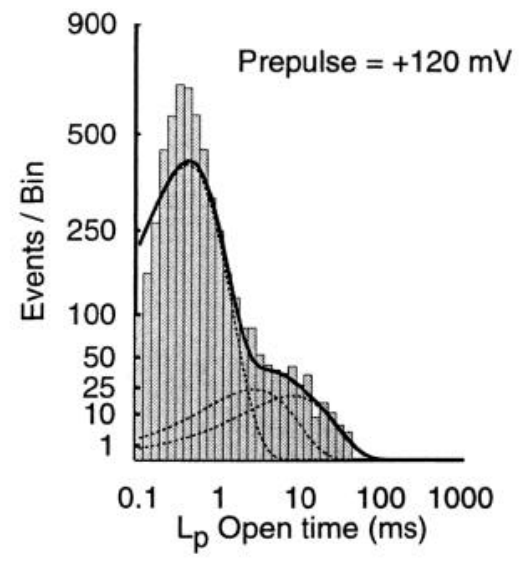

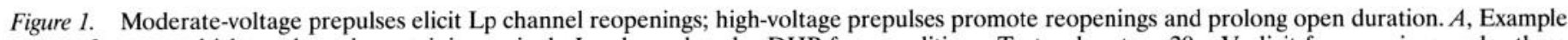

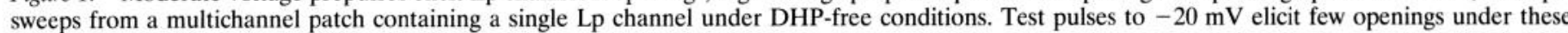

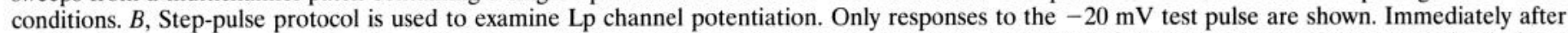

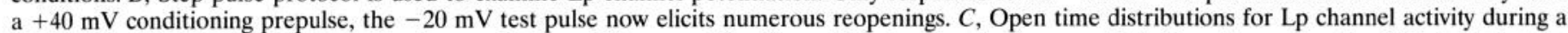

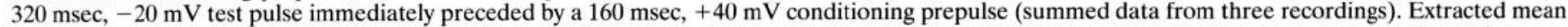

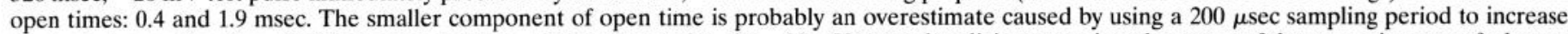

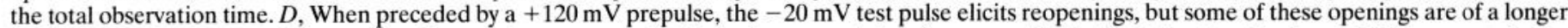

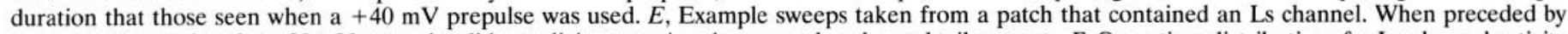

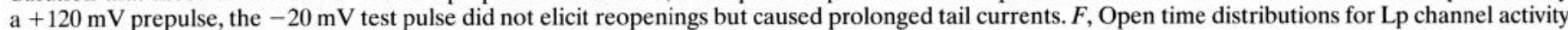

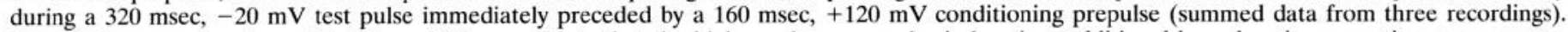

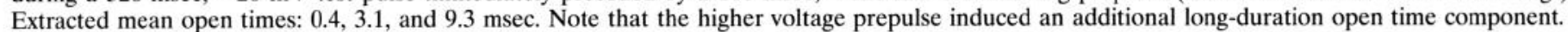

This was revealed by openings during the $-30 \mathrm{mV}$ test pulse (Fig. $2 A-C$, middle and right traces) that were observed only when the test pulse followed a conditioning prepulse. As can be seen in the individual sweeps, two kinds of voltage-dependent potentiation were found. One type was an LVP, because it was induced by relatively moderate prepulses $(+10$ to $+60 \mathrm{mV})$. This type was seen only in Lp channels (Fig. $2 A$, middle traces). A second type was a high-voltage potentiation (HVP), because significantly greater prepulse voltages (greater than $+60 \mathrm{mV}$ ) were required to elicit it. This was seen in Lp, Ls, and Lc channels (Fig. 2A-C, right traces).

We quantified this difference between LVP and HVP by measuring opening probability during a test pulse as a function of prepulse potential (Fig. 2D,E). As expected, voltage-dependent potentiation in the $\mathrm{Lp}$ channel was a two-component process in which moderate prepulses increased opening frequency (LVP only), and large prepulses increased both opening frequency and duration (LVP + HVP), giving rise to significantly greater activity (Fig. $2 D ; P o_{+120}=0.06 \pm 0.016$ vs $\mathrm{Po}_{+40}=0.0275 \pm 0.01 ; p<$ $0.005 ; n=6)$. In contrast, Ls channel potentiation was composed of a single component (HVP) elicited by high voltages $(n=7$; Fig. $2 E$, diamonds). Recordings from Lc channels showed results similar to those of hippocampal Ls channels ( $n=4$; Fig. $2 E$, triangles).

An additional difference between LVP and HVP was revealed by an analysis of Lp channel open times and Ls tailcurrent durations during test pulses preceded by either +40 or $+120 \mathrm{mV}$ prepulses (Fig. 3). In these recordings, we found that the high-voltage prepulses produced open time components in Lp, Ls, and Lc channels that were significantly larger than those found with moderate voltage prepulses (overall means: Lp, 9.1 \pm 0.41 vs $4.26 \pm 0.24 \mathrm{msec}, p<0.001 ; \mathrm{Ls}, 28.32 \pm 2.11$ vs 10.53 $\pm 2.45 \mathrm{msec}, p<0.001 ; \mathrm{Lc}, 35.81 \pm 5.62$ vs $9.35 \pm 3.46 \mathrm{msec}$, $p<0.001)$. Fitting the open time distributions with sums of three exponentials showed that this was attributable primarily 
A Lp channel

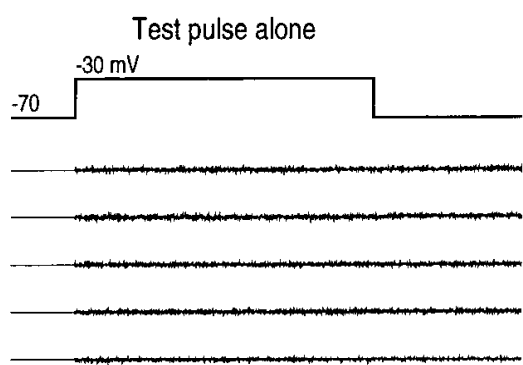

B Ls channel

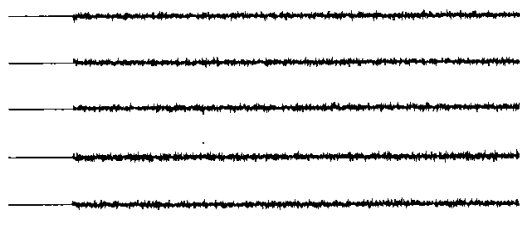

C Cardiac L channel (LC)

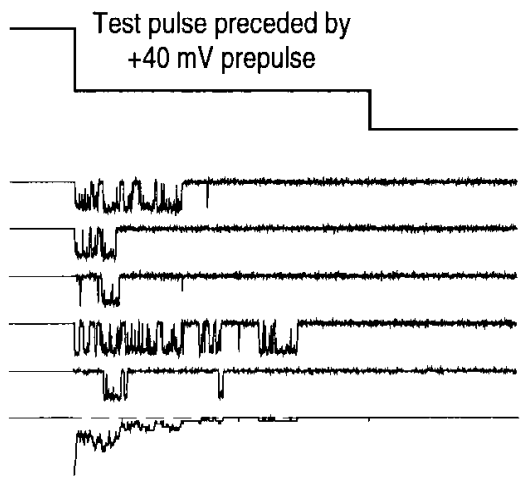

+40 mV prepulse

Test pulse preceded by $+120 \mathrm{mV}$ prepulse
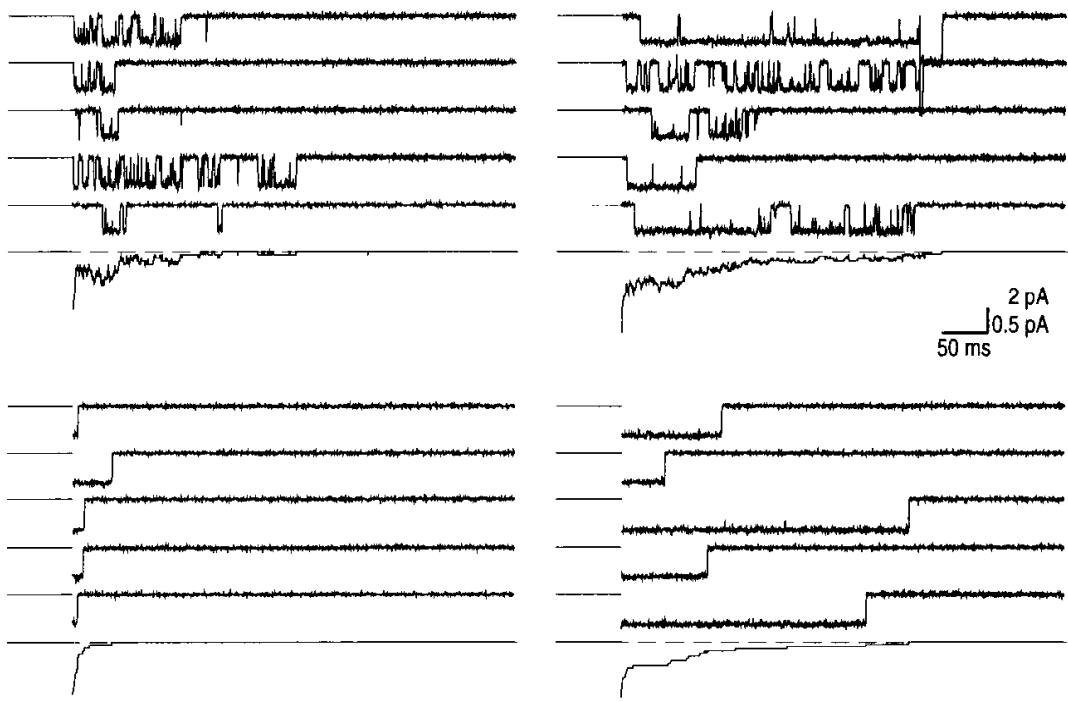

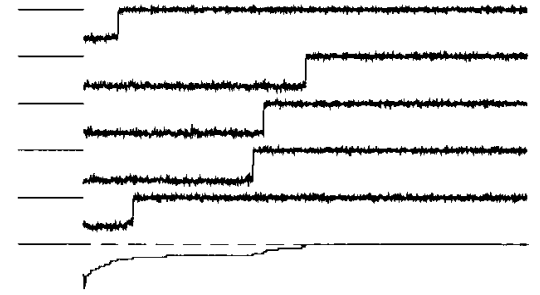

E
D

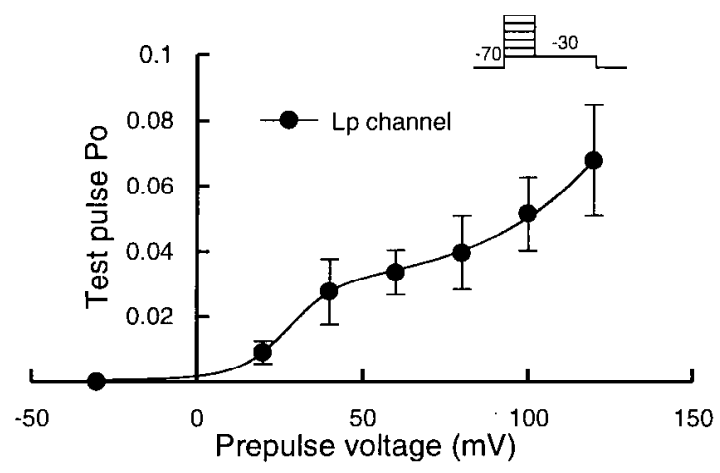

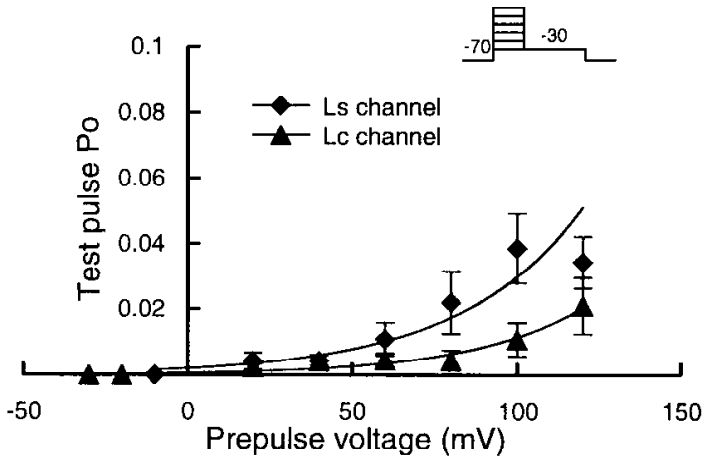

Figure 2. Two types of voltage-dependent potentiation in hippocampal Lp and Ls calcium channels. $A-C$, Examples of cell-attached single-channel recordings from patches containing only a single $\mathrm{Lp}, \mathrm{Ls}$, or $\mathrm{Lc}$ channel, respectively. Calcium channel potentiation was assessed during test pulses to -30 $\mathrm{mV}$ from a holding potential of $-70 \mathrm{mV}$ optionally preceded by prepulse depolarizations to +40 and $+120 \mathrm{mV}$. Only activity during the test pulse is shown. Bottom traces for +40 and $+120 \mathrm{mV}$ show average currents (Lp, 40 and 50 sweeps, respectively; Ls, 50 sweeps for each; Lc, 46 and 66 sweeps, respectively). $D, E$, Mean open probability $\pm \mathrm{SEM}$ at $-30 \mathrm{mV}$ versus prepulse potential plots for hippocampal $\mathrm{Lp}(\mathbf{Q} ; n=6 \mathrm{recordings})$ and $\mathrm{Ls}(\bullet ; n$ $=7$ recordings $)$ and cardiac $\operatorname{Lc}(\boldsymbol{\Delta} ; n=4$ recordings) channels. Lp channel plot is fitted with the sum of a Boltzmann and a single rising exponential function $\left(0.001 \times \exp \left(0029 \times V_{\text {pre }}\right)+0.027 \times\left[1+\exp \left\{\left(27.7-V_{\text {pre }}\right) / 7.018\right\}\right]^{-1}\right)$, whereas curves for neuronal Ls and cardiac Lc channels are fitted with single rising exponential functions [neuronal Ls, $0.002 \times \exp \left(0.027 \times V_{\text {prc }}\right)$; cardiac Ls, $0.0006 \times \exp \left(0.029 \times V_{\text {prc }}\right)$ ]. Open probabilities were obtained from sweeps idealized with a half-amplitude crossing criterion and cubic spline interpolation. Curves were fitted using the mean least-squares method. 
A Lp channel
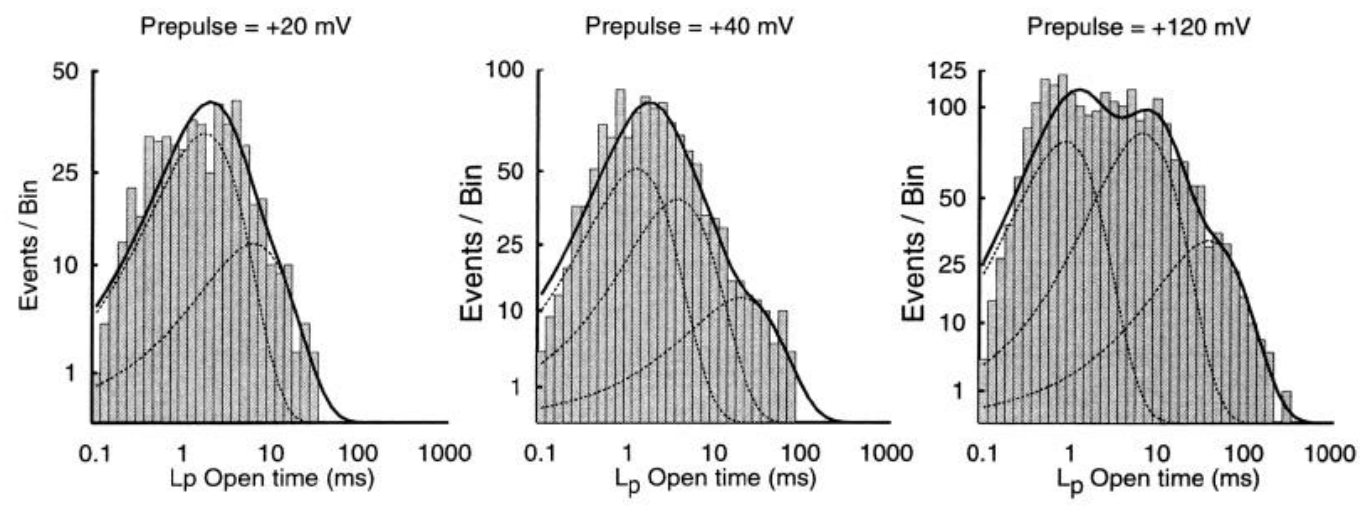

B Ls/Lc channel
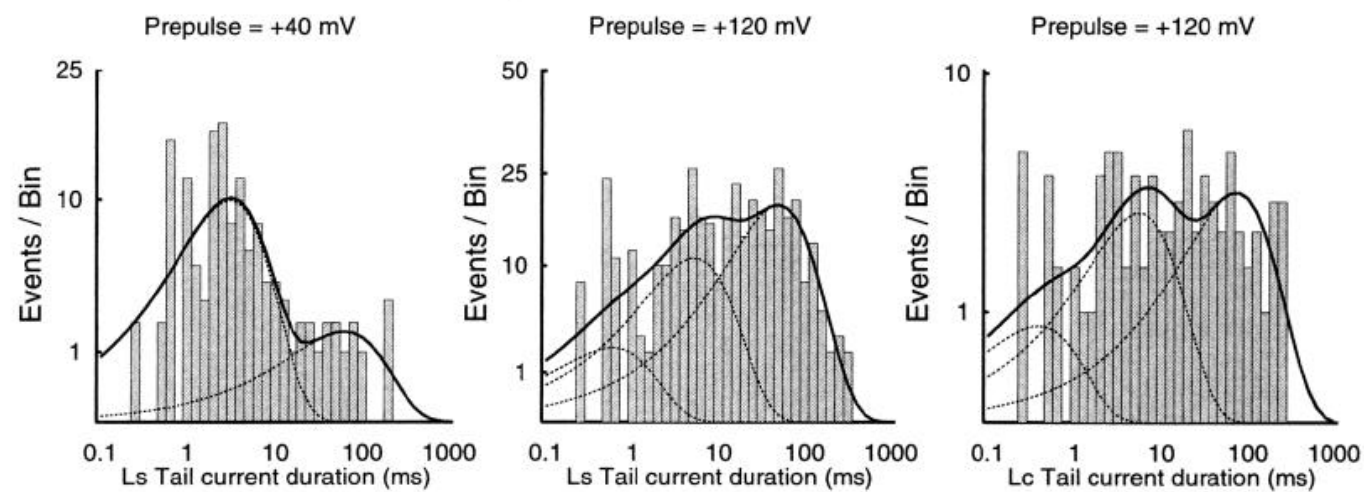

Figure 3. Large prepulses increase the relative proportions of long-duration openings and tail currents in Lp, Ls, and Lc channels. A, Open time histograms for Lp channel activity at $-30 \mathrm{mV}$ after $+20,+40$, and $+120 \mathrm{mV}$ prepulses, respectively $(n=6$ recordings). Open time values were plotted on square root-log coordinates, and mean open times were estimated from maximum likelihood fitting (Sigworth and Sine, 1987). Dotted lines show individual components, and solid lines show sum. Note that the prevalence of long-duration openings (bins of $>50$ msec) increased with the larger prepulse potentials. Extracted mean open times: 1.97 and $7.11 \mathrm{msec}$ for $+20 \mathrm{mV}$ prepulse; $1.42,4.25$, and $23.24 \mathrm{msec}$ for $+40 \mathrm{mV}$ prepulse; $0.97,7.63$, and 43.57 msec for $+120 \mathrm{mV}$ prepulse. $B$, Tail-current durations for Ls and Lc channels at $-30 \mathrm{mV}$. Again, note the increased tendency to long-duration openings at higher prepulse potentials. Extracted values for Ls channel: 3.42 and $69.54 \mathrm{msec}$ for $+40 \mathrm{mV}$ prepulse; $0.66,5.92$, and $55.79 \mathrm{msec}$ for $+120 \mathrm{mV}$ prepulse ( $n=7$ recordings). Extracted values for Lc channel: $0.43,6.25$, and $82.21 \mathrm{msec}$ for $+120 \mathrm{mV}$ prepulse $(n=4$ recordings).

to an increase in the duration of the two longest components for Lp channels and an increased prevalence of long $(>50$ msec) tail currents for Ls and Lc channels. Thus, like calcium channel potentiation in cardiac myocytes (Pietrobon and Hess, 1990), HVP consisted largely of prolonged tail currents during the test pulse that had originated from openings in the prepulse. LVP, however, was characterized by additional channel openings during the test pulse and not from prolonged tail currents.

It has been reported that cardiac L-type channel potentiation is not seen after transient hyperpolarization (Foley and Pelzer, 1994). This suggested to us that dual-pulse protocols (similar to the step-pulse protocol except that a voltage pulse to the holding potential is interposed between the conditioning prepulse and the test pulse) could be used to distinguish LVP from HVP. To test this, we examined the responses of Lp, Ls, and Lc channels to +10 $\mathrm{mV}$ voltage pulses alone and also after conditioning prepulses (+40 mV for Lp channel LVP and $+120 \mathrm{mV}$ for Ls/Lc channel HVP). When prepulses were used, they were separated from the test pulse by a $20 \mathrm{msec}$ hyperpolarization to $-90 \mathrm{mV}$. When this protocol was used, recordings from $\mathrm{Lp}$ channels showed clear potentiation of activity when the test pulse was preceded by a conditioning prepulse, despite the transient hyperpolarization
(Fig. 4A; compare left and middle sweeps). This effect was robust and could be seen with test pulses ranging from -40 to $+20 \mathrm{mV}$ (Fig. $4 A$, right plot).

Unlike LVP in Lp channels, HVP in Ls and Lc channels was not observed when dual-pulse protocols were used (Fig. 4B,C). Channel activity during $+10 \mathrm{mV}$ test pulses was not affected by a +120 $\mathrm{mV}$ prepulse if the prepulse was separated from the test pulse by a $20 \mathrm{msec}$ hyperpolarization to $-90 \mathrm{mV}$ (Fig. $4 B, C$, see sweeps). This was true for all test pulses examined, ranging from -20 to $+30 \mathrm{mV}$ (Fig. 4B,C, right plots).

When data from several recordings were combined, the effect of the interpulse hyperpolarization was found to be consistent (Fig. 5 ). The average open probability of an Lp channel during a +10 $\mathrm{mV}$ test pulse was $0.068 \pm 0.008$, whereas the open probability during a test pulse preceded by a prepulse was $0.099 \pm 0.006$, which is a significant increase in activity $(p<0.05 ; n=3)$. For Ls and Lc channels, however, activity measured during the test pulse alone $(0.077 \pm 0.019)$ was not different from activity measured during a test pulse preceded by a prepulse $(0.073 \pm 0.024$; $p>0.9 ; n=13$ ).

The dual-pulse experiments above indicate that HVP in Ls and Lc channels is eliminated by transient hyperpolarization and is therefore different from LVP in the Lp channel. They do 

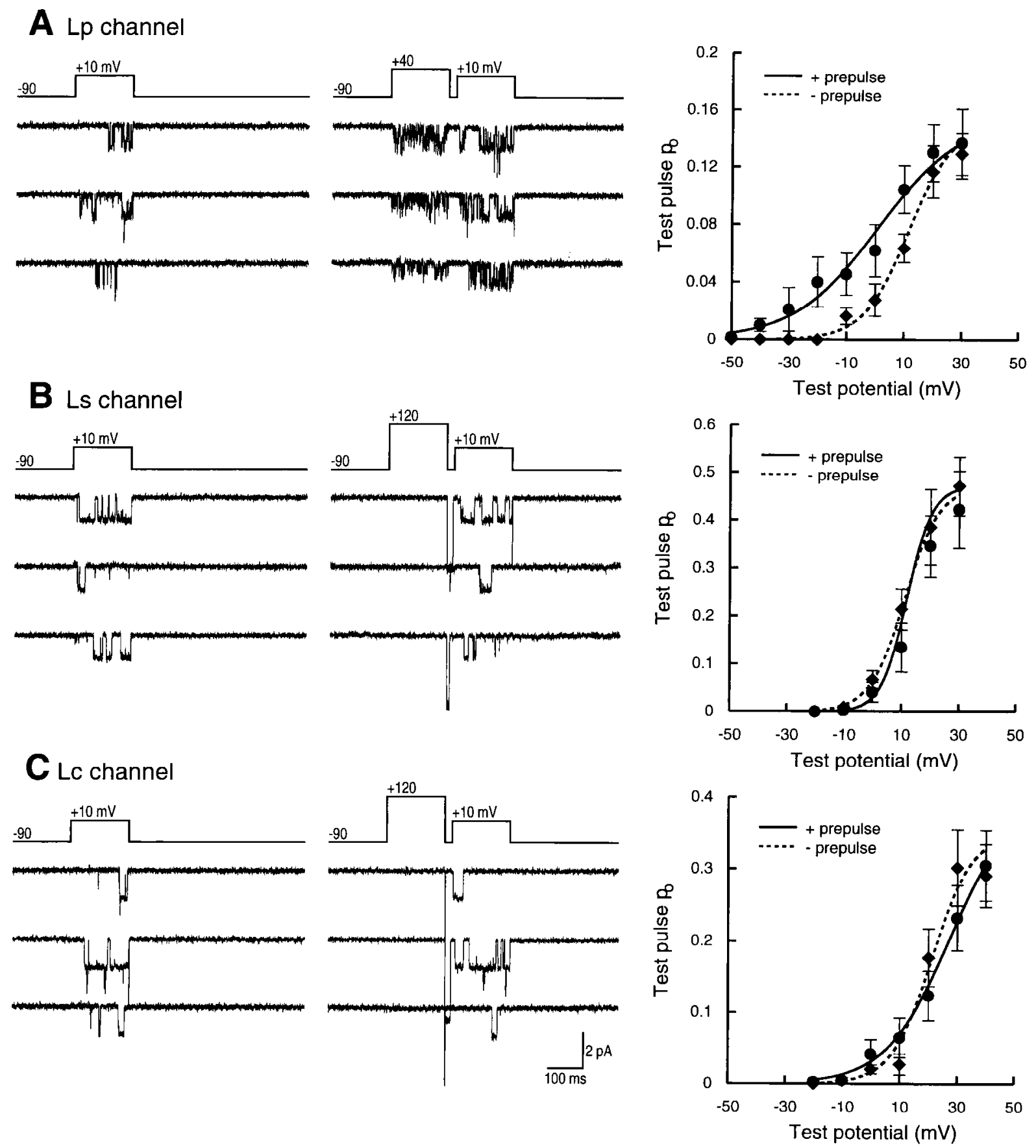

Figure 4. Transient hyperpolarization eliminates HVP but not LVP. A, Representative sweeps from a patch containing two Lp channels. Left sweeps show responses to a $+10 \mathrm{mV}$ test pulse. Middle sweeps show responses to an identical test pulse that has been preceded by $20 \mathrm{msec}$ with a conditioning prepulse to $140 \mathrm{mV}$. Note that activity during the test pulse was increased in the dual pulse paradigm compared with the test pulse alone. The right plot shows the effect of a $+40 \mathrm{mV}$ prepulse on test pulses to different potentials $(\bullet, \bullet)$. Test pulse open probability is plotted against test pulse potential either preceded by a prepulse (solid line) or alone (dashed line). All data shown are taken from a single recording; error bars indicate intertrial variability. $B$, Recording from a patch containing a single Ls channel with format similar to $A$. Note that the prepulse does not increase activity in a test pulse when a $20 \mathrm{msec}$ interpulse interval at $-90 \mathrm{mV}$ is present. This is reflected in the plot of test pulse open probability versus test pulse potential. Test pulse activity alone (dashed line) is not different from activity during a test pulse preceded by a prepulse (solid line). $C$, Recording from a patch containing two Lc channels with the same format as $B$. Note that HVP in the Lc channel resembles that of the hippocampal neuron Ls channel.

not prove, however, that this same separation can hold true within a single-channel type, namely the Lp channel. To determine whether LVP and HVP were attributable to independent processes, we again interposed a transient hyperpolarization between the prepulse and test pulse and examined Lp channel activity. In these experiments, however, we examined the ef- fects of both $+40 \mathrm{mV}$ and $+120 \mathrm{mV}$ prepulses on Lp channels during $-30 \mathrm{mV}$ test pulses. As before, test pulses alone elicited essentially no Lp channel openings (Fig. 6A, left traces). Significant activity was seen when test pulses were preceded by prepulses to either +40 or $+120 \mathrm{mV}$ (Fig. $6 \mathrm{~A}$, middle and right traces). Unlike the protocol with no interposed hyperpolariza- 


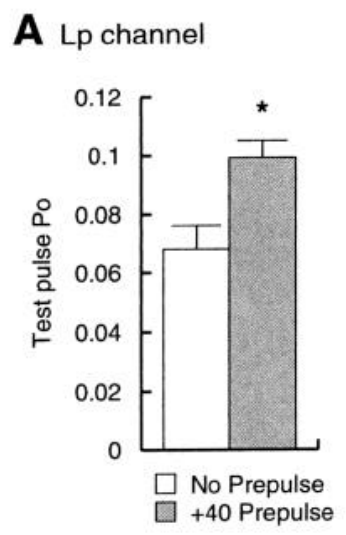

B Ls/Lc channel

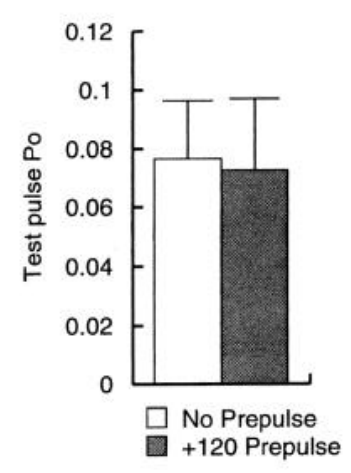

Figure 5. Summary data for dual-pulse experiments on Lp, Ls, and Lc channels. $A$, Plot of Lp channel activity shows test pulse $(+10 \mathrm{mV})$ open probability when either presented alone (white bar) or preceded by a conditioning prepulse to $+40 \mathrm{mV}$ (shaded bar). The increased activity during the prepulse after the conditioning pulse is statistically significant $(p<0.05 ; n=3)$. The interpulse was $-90 \mathrm{mV}$ for $20 \mathrm{msec}$. $B$, Combined data for Ls and Lc channels. The activity during the test pulse was not significantly different when preceded by a conditioning prepulse (shaded bar $)$ if the membrane was hyperpolarized between the two pulses ( $p>0.9$; $n=13$ ). Test pulse, $+10 \mathrm{mV}$; interpulse, $-90 \mathrm{mV}$ for $20 \mathrm{msec}$.

tion (Fig. 2A), however, the higher prepulse voltage did not evoke the long openings characteristic of HVP but still increased the number of openings indicative of LVP. Thus, the higher prepulse voltage did not significantly increase the potentiation measured by the test pulse $\left(P o_{+40}=0.04 \pm 0.006 \mathrm{vs}\right.$ $\left.P o_{+120}=0.038 \pm 0.001 ; p>0.7 ; n=7\right)$. Furthermore, responses to test pulses as a function of a series of prepulse potentials showed a single saturating function (Fig. 6B), unlike the biphasic one found in the earlier experiments (Fig. 2D). Moreover, there was no difference in the open time distributions of test-pulse activity with +40 or $+120 \mathrm{mV}$ prepulses (overall means: $2.89 \pm 0.11$ vs $2.9 \pm 0.10 \mathrm{msec} ; p>0.9$; Fig. $6 C, D)$. The magnitude of potentiation decreased with increasing interpulse duration, although comparable results were obtained with interpulse durations up to $150 \mathrm{msec}$ at $-90 \mathrm{mV}$.

To examine the features of LVP and HVP at the macroscopic level, we made a series of whole-cell recordings and evaluated tail currents at $-40 \mathrm{mV}$ after prepulses from -30 to $+100 \mathrm{mV}$. Inspection of individual traces showed that as the prepulse voltage was made larger, the amplitude of the tail current increased and additional slow components were added (Fig. 7A). Based on our single-channel recordings and the work of others (Swandulla and Armstrong, 1988; Plummer et al., 1991; Regan et al., 1991; Kasai and Neher, 1992; Randall and Tsien, 1995), the rapid component of current represents deactivation of nonpotentiated DHPsensitive channels and non-DHP-sensitive channels (i.e., N, P, Q, and R), which have been found to be similar in a number of preparations. The slow component of the whole-cell tail current is attributable to prolonged activity of potentiated Lp and Ls channels. Because the holding potential was $-40 \mathrm{mV}$, this slow component cannot be attributable to deactivation of T-type channels because they are inactivated at this voltage (Carbone and Lux, 1987).

We analyzed the whole-cell recordings by measuring the amplitude of the tail current as a function of the test potential (Fig. 7). To study the rapid component, tail-current amplitude was measured at $500 \mu \mathrm{sec}$. The resulting curve showed an approximation of a Boltzmann relationship, which was expected because this time point should represent activation of all components of calcium current in these cells (Fig. $7 B$, inset). We were more interested in the slower components, however, because these should be attributable to prolonged calcium channel activity caused by potentiation. Accordingly, we quantified tail-current amplitude at a series of time points $(5,10,15,30$, and $100 \mathrm{msec})$ after repolarization (Fig. $7 B$ ).

At 5 and $10 \mathrm{msec}$ after repolarization, the tail currents showed a biphasic increase as the test potential was increased (Fig. $7 B$, circles, triangles). Because non-DHP-sensitive currents have decayed almost completely by this time, these measurements no longer represent channel activation but should instead be indicative of potentiated Lp and Ls channel activity. Consistent with our single-channel recordings, we found that the curves were composed of two components, one that was elicited by low voltages and a second that was seen only with high-voltage prepulses. Moreover, the normalized amplitudes of the tail currents elicited by the $+100 \mathrm{mV}$ depolarization were significantly greater than those produced by the $+40 \mathrm{mV}$ depolarization $(5 \mathrm{msec}: n=16, p$ $<0.001 ; 10$ msec: $n=15, p<0.01$ ), again in good agreement with the single-channel data.

When tail-current amplitudes were measured at increasingly longer times after repolarization, the shape of the curve changed, gradually losing much of the high-voltage component (Fig. $7 B$, diamonds, stars). Although the whole-cell recording technique makes identification of channel type less certain, these data suggest that HVP decayed more rapidly than LVP at $-40 \mathrm{mV}$. This interpretation agrees with our single-channel recordings in the absence of DHP agonist, which showed that the duration of potentiated Ls channel activity was much shorter than potentiated Lp channel activity (Fig. 1). In support of this conclusion, the normalized tail-current amplitudes at these time points in response to +100 and $+40 \mathrm{mV}$ depolarizations were no longer significantly different (15 msec: $n=10, p>0.1 ; 30 \mathrm{msec}: n=10$, $p>0.5)$. These observations also complement the dual-pulse experiments on Lp channels in which the $+120 \mathrm{mV}$ prepulses did not prolong Lp channel open time, although they did increase the number of Lp channel reopenings (Fig. 6).

\section{DISCUSSION}

In hippocampal neurons, it has been reported that depolarization can induce DHP-sensitive calcium channel reopenings at negative potentials (Fisher et al., 1990; Thibault et al., 1993), which is voltage-dependent potentiation and not recovery from inactivation (Kavalali and Plummer, 1994). This potentiation, however, is not uniformly present in L-type channels. Instead, we have shown that there are multiple kinds of DHP-sensitive channels and two distinct types of potentiation that differ in the voltages required to elicit them and in the voltage-dependence of their decay. LVP is found exclusively in Lp channels, whereas HVP is found in both neuronal Lp and Ls channels and is indistinguishable from that seen in rat cardiac L-type channels. These two kinds of potentiation work via distinct mechanisms, because they can be separated from one another in the Lp channel by using dual-pulse protocols with a brief hyperpolarization interposed between the conditioning and test pulses.

In the present study, the DHP agonist (+)-S-202-791 was used to identify Ls and Lp-type calcium channels in single-channel recordings unequivocally. Because this compound is known to alter the voltage-dependence and open probability of responsive calcium channels, we also made whole-cell recordings without agonist to determine the voltage-dependence and magnitude of 
A Lp channel

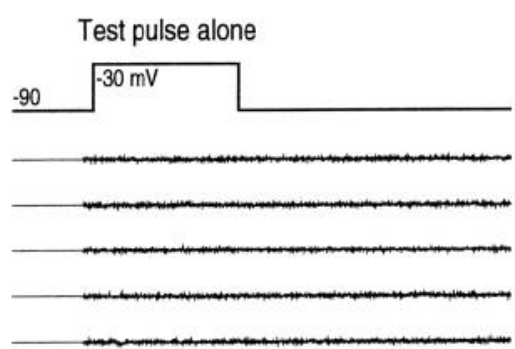

B

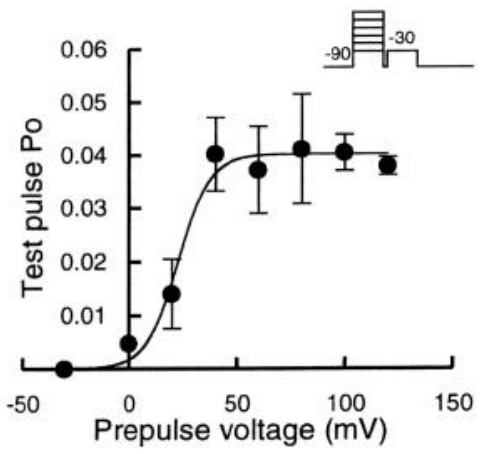

20 msec delay between test pulse and $+40 \mathrm{mV}$ prepulse

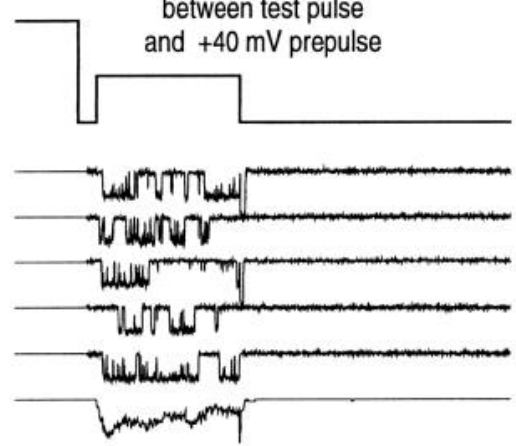

C

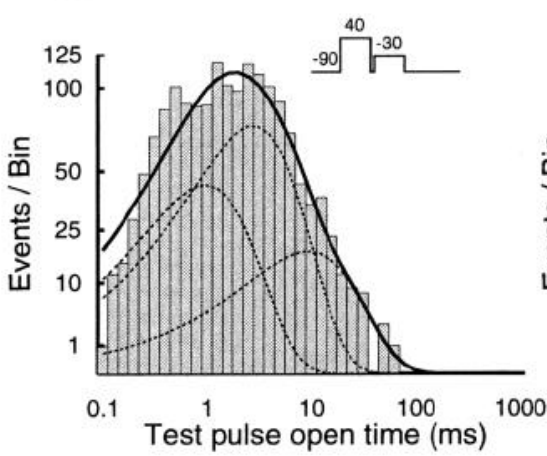

20 msec delay

between test pulse

and $+120 \mathrm{mV}$ prepulse

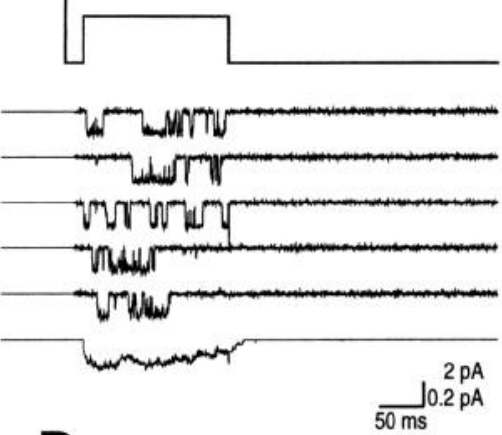

D

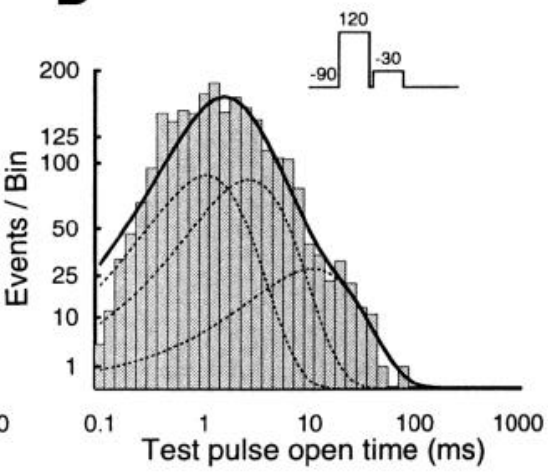

Figure 6. Dual-pulse protocols selectively remove HVP in hippocampal Lp channels. $A$, Representative sweeps from a dual-pulse experiment that illustrate the response of an $\mathrm{Lp}$ channel to a test pulse of $-30 \mathrm{mV}$ that was optionally preceded by a prepulse to $+40 \mathrm{or}+120 \mathrm{mV}$ with a delay of 20 $\mathrm{msec}$ at $-90 \mathrm{mV}$. Bottom trace for $+40 \mathrm{mV}$ prepulse depicts an average of 122 sweeps and for $+120 \mathrm{mV}$ prepulse depicts an average of 209 sweeps. $B$, Mean open probability \pm SEM ( filled circles) versus prepulse potential plot for the Lp channel activity at $-30 \mathrm{mV}(n=7)$ can be fitted with a Boltzmann function $\left(0.039 \times\left[1+\exp \left\{\left(22.83-V_{\text {pre }}\right) / 7.415\right\}\right]^{-1}\right)$ (smooth curve $) . C, D$, Open time distributions at $-30 \mathrm{mV}$ for the Lp channel can be fitted with three exponentials for both +40 and $+120 \mathrm{mV}$ prepulses $(n=7)$. Dotted lines show individual components, and solid line shows sum. Extracted mean open times: $1.09,3.14$, and $10.69 \mathrm{msec}$ for $+40 \mathrm{mV} ; 1.18,3.00$, and $12.18 \mathrm{msec}$ for $+120 \mathrm{mV}$ prepulse. Note that there is little difference in the distributions at $-30 \mathrm{mV}$ with regard to long-duration openings.

LVP and HVP under more physiological conditions. As expected, the voltages required to elicit LVP and HVP were $\sim 27 \mathrm{mV}$ more negative in whole-cell recordings, a result in accordance with the reduced screening of surface charge by the lower divalent cation concentration. Moreover, the whole-cell recordings also showed that LVP and HVP can cause significant calcium entry after a conditioning depolarization, attributable largely to the increased driving force at the negative resting potentials. The data also suggest that LVP and perhaps HVP could be elicited by strong neuronal activity such as bursts of action potentials, because these voltage changes are well within the range required for initiation of calcium channel potentiation.

Although no formal distinctions have been made, calcium channel potentiation is not identical in the cell types in which it has been observed. For example, calcium channel potentiation in cardiac myocytes decays rapidly at negative potentials (Pietrobon and Hess, 1990; Sculptoreanu et al., 1993a) and is abolished by transient hyperpolarization in dual-pulse protocol experiments (Foley and Pelzer, 1994). This is unlike potentiation in adrenal chromaffin cells, which typically has been studied by interposing a brief hyperpolarization to $-80 \mathrm{mV}$ between the conditioning prepulse and the test pulse (Hoshi et al., 1984; Artalejo et al., 1991a). Moreover, the voltages required to elicit potentiation differ as well. Cardiac L-type channel potentiation requires relatively high voltages (greater than $+50 \mathrm{mV}$ ), whereas adrenal chromaffin cell potentiation can be elicited by lower voltages.
Calcium channel potentiation in different cell types can also be distinguished pharmacologically. In adrenal chromaffin cells, it is saturated by the addition of the DHP agonist Bay K 8644 (Artalejo et al., 1991a) and can be blocked by the protein kinase inhibitor H-7 (Artalejo et al., 1992), giving rise to the notion that the mechanism of potentiation involves voltage-dependent phosphorylation. Conversely, potentiation of cardiac L-type channels is not prevented by DHP agonists (Sculptoreanu et al., 1993a) and is insensitive to H-7 (Foley and Pelzer, 1994), although it can be blocked by specific inhibitors of protein kinase A (Sculptoreanu et al., 1993a).

At present, we can only speculate about the processes that give rise to the two kinds of potentiation. We currently hypothesize that $\mathrm{Lp}$ and $\mathrm{Ls}$ channel activities are attributable to entirely different molecular complexes. One possibility is that LVP and HVP represent electrophysiological phenotypes of $\alpha_{1 \mathrm{C}}$ and $\alpha_{1 \mathrm{D}}$ subunits, because they are both present in hippocampal neurons (Hell et al., 1993a). A second possibility is that the two channel types share the same $\alpha$ subunit but show distinctive properties because of characteristic interactions with specific $\beta$ subunits. There is now considerable evidence that $\beta$ subunits play a crucial role in the determination of calcium channel properties (Neely et al., 1993; De Waard et al., 1994; Berrow et al., 1995; Pérez-García et al., 1995), and there is some indication that a form of potentiation depends critically on their presence (Bourinet et al., 1994). 

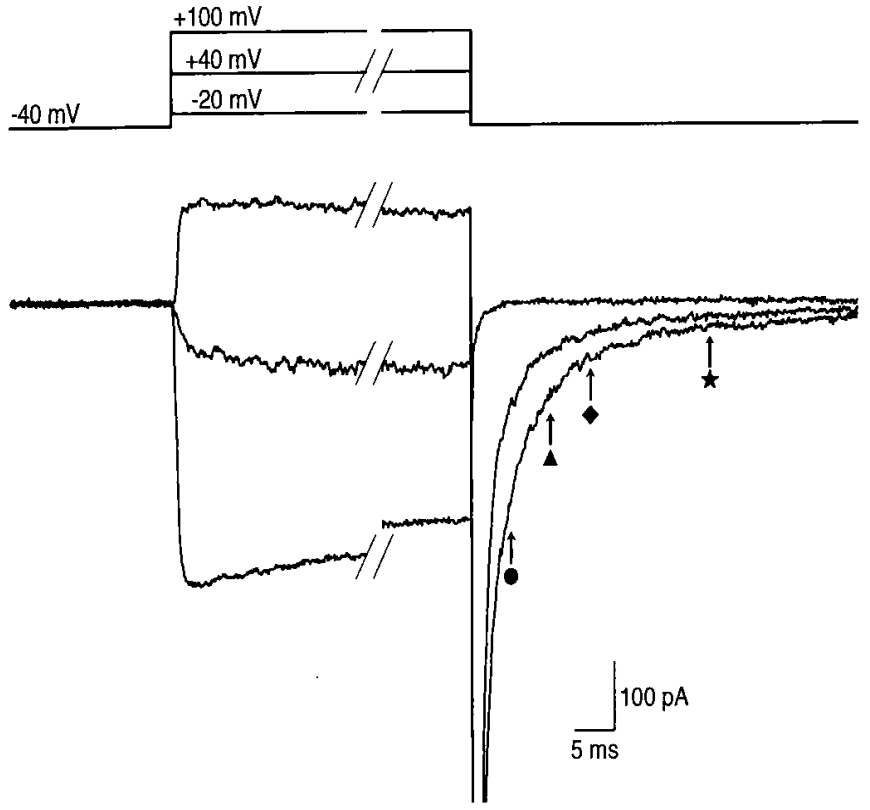

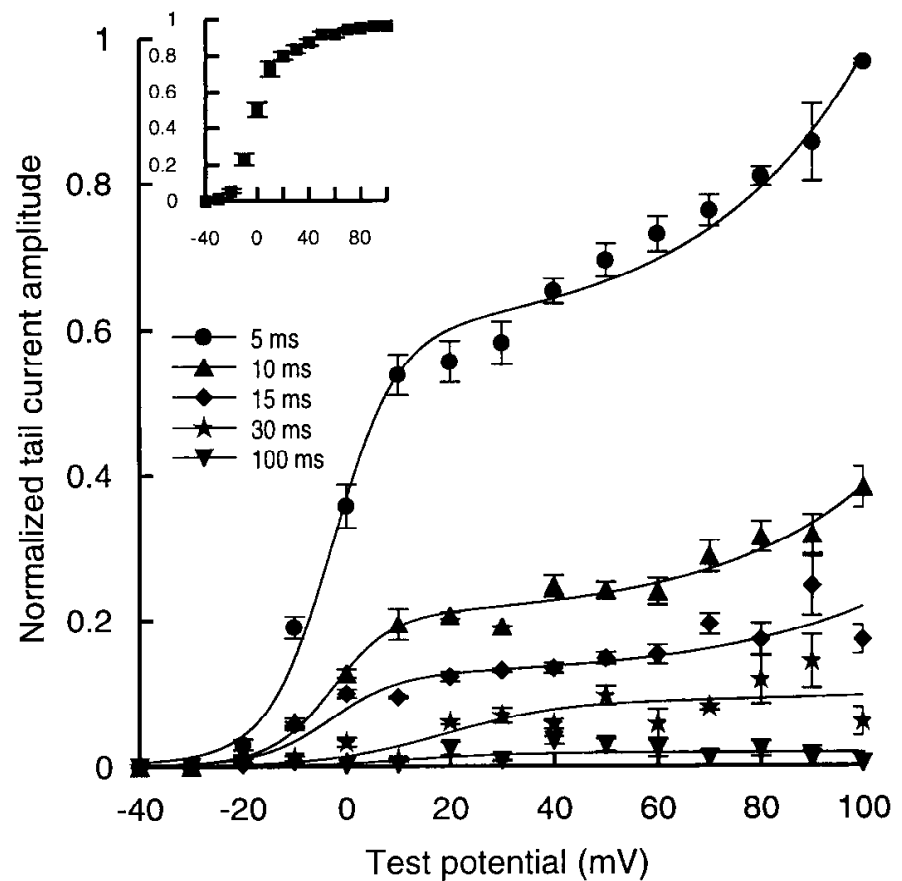

Figure 7. Whole-cell recordings show prolonged tail currents resulting from LVP and HVP. $A$, Example sweeps from a whole-cell recording showing responses to three different voltage pulses and tail currents to the same repolarization potential. The traces are shown at an expanded time scale to illustrate the characteristics of the tail currents, and the indicated portions of the sweeps have been removed. Note that as the depolarization voltage increased, additional components of tail current were added. Symbols with arrows indicate the time points at which measurements of amplitude were taken. $B$, Plot of tail-current amplitude versus prepulsc potential at several time points after repolarization. Each point represents measurements from $10-16$ recordings \pm SEM. Values are normalized for each experiment to the maximum tail current measured at the 5 msec time point (typically from the test voltage to $+100 \mathrm{mV}$ ). Data points for each series are fit with the sum of a Boltzmann distribution and an exponential (same formula as in Fig. 2). Although it would presumably be more appropriate, the sum of two Boltzmann distributions was not used because a maximum value for the second distribution could not be obtained. As the time after repolarization increased, the exponential component decreased until it was no longer a significant part of the function. Inset shows measurement of activation of all components of whole-cell calcium current (tail-current amplitude at $500 \mu s e c$ after repolarization). Values are normalized to the maximum current measured at $500 \mu \mathrm{sec}$ (typically from the test voltage to $+100 \mathrm{mV}$ ).

Furthermore, the regulation of $\alpha$ and $\beta$ subunits by phospliorylation could be involved (Hell et al., 1993b) (for review, see Isom et al., 1994).

Voltage-dependent enhancement of calcium channel activity has been reported in various cell types and for several kinds of calcium channels. In most cases, this enhancement of activity has been limited to DHP-sensitive channels, although a voltagedependent relief of tonic $G$-protein-dependent inhibition has been reported for $\mathrm{N}$-type calcium channels (Elmslie et al., 1990; Ikcda, 1991; Kasai, 1991). This kind of activity, however, is very different from the enhancement of DHP-sensitive calcium channel activity, which does not seem to be a modulation of inhibition.

In cerebellar granule cells, Forti and Pietrobon (1993) have reported a kind of calcium channel gating ("anomalous gating"), distinct from LVP and HVP, that is characterized by reduced activity during depolarizing voltage pulses followed by increased activity during repolarization to a negative holding potential. The increased activity during repolarization also involves a shift from brief openings to prolonged openings and is not attributable to recovery from inactivation (but see Slesinger and Lansman, 1991). These features readily distinguish the anomalous gating channel in cerebellar granule neurons from the Lp channel in hippocampal neurons and suggest that the kinds of voltage-dependent potentiation found in neurons may be cell type-specific.

Much of what is known about potentiation of DHP-sensitive calcium channels comes from work on adrenal chromaffin cells. Early studies by Fenwick et al. (1982) and Hoshi et al. (1984) showed that chromaffin cell calcium current could be enhanced by conditioning prepulses. At the single-channel level, this has been shown to be the result of a prolongation of channel open time (Hoshi and Smith, 1987). Artalejo et al. (1991b) suggested this activity was attributable to a novel kind of DHP-sensitive "facilitation" channel in which potentiation requires voltage-dependent phosphorylation by an unidentified protein kinase (Artalejo et al., 1992). A similar voltage-dependent mechanism of potentiation has been seen in skeletal muscle and cardiac $\alpha_{1}$ subunits (Sculptoreanu et al., 1993a,b; Johnson et al., 1994). Facilitation of smooth muscle $\alpha_{1}$-subunit calcium channels, however, has been shown to be independent of phosphorylation (Kleppisch et al., 1994). Our preliminary work with protein kinase inhibitors has shown HVP and LVP to be resistant to compounds such as $\mathrm{H}-7$ and $\mathrm{H}-89$. Thus, it may be that these forms of potentiation also do not require phosphorylation.

There are numerous functional implications of calcium channel potentiation, including increased catecholamine secretion from the adrenal gland during stress (Artalejo et al., 1991a) and enhanced muscle contractility after trains of action potentials (Noble and Shimoni, 1981; Lee, 1987; Zygmunt and Maylie, 1990). In neurons, DHP-sensitive calcium channel activity has been associated with increases in synaptic strength (Johnston et al., 1992; 
Kullmann et al., 1992; Hanse and Gustafsson, 1994), alterations in action potential firing rates (Thompson et al., 1990), and agingrelated learning deficits (Pitler and Landfield, 1990; Disterhoft et al., 1994; Landfield, 1994). Voltage-dependent increases in the activity of DHP-sensitive calcium channels may also regulate the duration and frequency of calcium-dependent spikes found in soma and dendrites of hippocampal neurons (Wong and Prince, 1978; Benardo et al., 1982) as well as the amplitude and duration of afterpotentials that follow the $\mathrm{Na}^{+}$-dependent action potentials (Wong and Prince, 1981). This is supported by the presence of L-type calcium channel clusters in dendrites of hippocampal pyramidal cells and their potential contribution to dendritic activity in these neurons (Westenbroek et al., 1990; Hell et al., 1993a; Andreasen and Lambert, 1995; Magee and Johnston, 1995; Spruston et al., 1995).

To date, we have seen LVP exclusively in central neurons and not in rat cardiac myocytes, rat adrenal chromaffin cells, or rat sympathetic neurons. HVP occurs in both types of neuronal DHP-sensitive calcium channels after large prepulses. This suggests that LVP may be most relevant for processes that are unique to neurons. These two kinds of potentiation add a new level of complexity to the role of calcium as a potent modulator of hippocampal function.

\section{REFERENCES}

Andreasen M, Lambert JDC (1995) Regenerative properties of pyramidal cell dendrites in area $\mathrm{CA} 1$ of the rat hippocampus. $\mathbf{J}$ Physiol (Lond) 483:421-441.

Anwyl R (1991) Modulation of vertebrate neuronal calcium channels by transmitters. Brain Res Rev 16:265-281.

Artalejo CR, Dahmer MK, Perlman RL, Fox AP (1991a) Two types of $\mathrm{Ca}^{2+}$ currents are found in bovine chromaffin cells: facilitation is due to the recruitment of one type. J Physiol (Lond) 432:681-707.

Artalcjo CR, Mogul DJ, Perlman RL, Fox AP (1991b) Threc types of bovine chromaffin cell $\mathrm{Ca}^{2+}$ channels: facilitation increases the opening probability of a $27 \mathrm{pS}$ channel. J Physiol (Lond) 444:213-240.

Artalejo CR, Rossie S, Perlman RL, Fox AP (1992) Voltage-dependent phosphorylation may recruit $\mathrm{Ca}^{2+}$ current facilitation in chromaffin cells. Nature 358:63-66.

Augustine GJ, Charlton MP, Smith SJ (1987) Calcium action in synaptic transmitter release. Annu Rev Neurosci 10:633-693.

Bading H, Ginty DD, Greenberg ME (1993) Regulation of gene expression in hippocampal neurons by distinct calcium signaling pathways. Science 260:181-186.

Benardo LS, Masukawa LM, Prince DA (1982) Electrophysiology of isolated hippocampal pyramidal dendrites. J Neurosci 2:1614-1622.

Berrow NS, Campbell V, Fitzgerald EM, Brickley K, Dolphin AC (1995) Antisense depletion of $\beta$-subunits modulates the biophysical and pharmacological properties of neuronal calcium channels. J Physiol (Lond) 482:481-491.

Bertolino M, Llinas RR (1992) The central role of voltage-activated and receptor-operated calcium channels in neuronal cells. Annu Rev Pharmacol Toxicol 32:399-421.

Bourinet E, Charnet P, Tomlinson WJ, Stea A, Snutch TP, Nargeot J (1994) Voltage-dependent facilitation of a neuronal $\alpha$ 1C L-type calcium channel. FMBO J 13:50132-5039.

Carbone E, Lux HD (1987) Kinetics and selectivity of a low-voltageactivated calcium current in chick and rat sensory neurones. J Physiol (Lond) 386:547-570.

Clapp LH, Gurney AM (1991) Outward currents in rabbit pulmonary artery cells dissociated with a new technique. Exp Physiol 76:677-693.

Colquhoun D, Sigworth FJ (1983) Fitting and statistical analysis of single-channel records. In: Single-channel recording (Sakmann B, Neher E, eds), pp 191-263. New York: Plenum.

De Waard M, Pragnell M, Campbell KP (1994) $\mathrm{Ca}^{2+}$ channel regulation by a conserved beta subunit domain. Neuron 13:495-503.

Disterhoft JF, Moyer Jr JR, Thompson LT (1994) The calcium rationale in aging and Alzheimer's disease. Evidence from an animal model of normal aging. Ann NY Acad Sci 747:382-406.
Dolphin AC (1995) Voltage-dependent calcium channels and their modulation by neurotransmitters and G proteins. Exp Physiol 80:1-36.

Dunlap K, Luebke JI, Turner TJ (1995) Exocytotic $\mathrm{Ca}^{2+}$ channels in mammalian central neurons. Trends Neurosci 18:89 -98 .

Elmslie KS, Zhou W, Jones SW (1990) LHRH and GTP-gamma-S modify calcium current activation in bullfrog sympathetic neurons. Neuron 5:75-80.

Fenwick EM, Marty A, Neher E (1982) Sodium and calcium channels in bovine chromaffin cells. J Physiol (Lond) 331:599-635.

Fisher RE, Gray R, Johnston D (1990) Properties and distribution of single voltage-gated calcium channels in adult hippocampal neurons. J Neurophysiol 64:91-104.

Foley CF, Pelzer DJ (1994) Voltage-dependent recruitment of $\mathrm{Ca}^{2+}$ current facilitation in isolated ventricular myocytes from guinea-pig heart. J Physiol (Lond) 477:88P-89P.

Forti L, Pietrobon D (1993) Functional diversity of L-type calcium channels in rat cerebellar neurons. Neuron 10:437-450.

Hanse E, Gustafsson B (1994) TEA elicits two distinct potentiations of synaptic transmission in the CA1 region of the hippocampal slice. J Neurosci 14:5028-5034.

Hell JW, Westenbroek RE, Warner C, Ahlijanian MK, Prystay W, Gilbert MM, Snutch TP, Catterall WA (1993a) Identification and differential subcellular localization of the neuronal class $C$ and class D L-type calcium channel alpha 1 subunits. J Cell Biol 123:949-962.

Hell JW, Yokoyama CT, Wong ST, Warner C, Snutch TP, Catterall WA (1993b) Differential phosphorylation of two size forms of the neuronal class C L-type calcium channel $\alpha 1$ subunit. J Biol Chem 268:19451-19457.

Hoshi T, Smith SJ (1987) Large depolarization induces long openings of voltage-dependent calcium channels in adrenal chromaffin cells. J Neurosci 7:571-580.

Hoshi T, Rothlein J, Smith SJ (1984) Facilitation of $\mathrm{Ca}^{21}$-channel currents in bovine adrenal chromaffin cells. Proc Natl Acad Sci USA 81:5871-5875.

Ikeda SR (1991) Double-pulse calcium channel current facilitation in adult rat sympathetic neurones. J Physiol (Lond) 439:181-214.

Isom LL, De Jongh KS, Catterall WA (1994) Auxiliary subunits of voltage-gated ion channels. Neuron 12:1183-1194.

Johnson BD, Byerly L (1994) $\mathrm{Ca}^{2+}$ channel $\mathrm{Ca}^{2+}$-dependent inactivation in a mammalian central neuron involves the cytoskeleton. Pflügers Arch 429:14-21.

Johnson BD, Scheuer T, Catterall WA (1994) Voltage-dependent potentiation of L-type $\mathrm{Ca}^{2+}$ channels in skeletal muscle cells requires anchored cAMP-dependent protein kinase. Proc Natl Acad Sci USA 91:11492-11496.

Johnston D, Williams S, Jaffe D, Gray R (1992) NMDA-receptorindependent long-term potentiation. Annu Rev Physiol 54:489-505.

Kasai $H$ (1991) Tonic inhibition and rebound facilitation of a neuronal calcium channel by a GTP-binding protein. Proc Natl Acad Sci USA 88:8855-8859.

Kasai H, Neher E (1992) Dihydropyridine-sensitive and omegaconotoxin-sensitive calcium channels in a mammalian neuroblastomaglioma cell line. J Physiol (Lond) 448:161-188.

Kavalali ET, Plummer MR (1994) Sclective potentiation of a novel calcium channel in rat hippocampal neurones. J Physiol (Lond) 480:475-484.

Kleppisch T, Pedersen K, Strubing C, Bosse-Doenecke E, Flockerzi V, Hofmann F, Hescheler J (1994) Double-pulse facilitation of smooth muscle $\alpha_{1}$-subunit $\mathrm{Ca}^{2+}$ channels expressed in $\mathrm{CHO}$ cells. EMBO J 13:2502-2507.

Kullmann DM, Perkel DJ, Manabe T, Nicoll RA (1992) $\mathrm{Ca}^{2+}$ entry via postsynaptic voltage-sensitive $\mathrm{Ca}^{2+}$ channels can transiently potentiate excitatory synaptic transmission in the hippocampus. Neuron 9:1175-1183.

Landfield PW (1994) Increased hippocampal $\mathrm{Ca}^{2+}$ channel activity in brain aging and dementia. Hormonal and pharmacologic modulation. Ann NY Acad Sci 747:351-364.

Lee KS (1987) Potentiation of the calcium-channel currents of internally perfused mammalian heart cells by repetitive depolarization. Proc Natl Acad Sci USA 84:3941-3945.

Lu B, Yokoyama M, Dreyfus CF, Black IB (1991) NGF gene expression in actively growing brain glia. J Neurosci 11:318-326.

Magee JC, Johnston D (1995) Synaptic activation of voltage-gated channels in the dendrites of hippocampal pyramidal neurons. Science 268:301-304. 
Mintz IM, Venema VJ, Swiderek KM, Lee TD, Bean BP, Adams ME (1992) P-type calcium channels blocked by the spider toxin omega-AgaIVA. Nature 355:827-829.

Morgan JI, Curran T (1986) Role of ion flux in the control of c-fos expression. Nature 322:552-555

Murphy TH, Worley PF, Baraban JM (1991) L-type voltage-sensitive calcium channels mediate synaptic activation of immediate carly genes. Neuron 7:625-635.

Neely A, Wei X, Olcese R, Birnbaumer L, Stefani E (1993) Potentiation by the beta subunit of the ratio of the ionic current to the charge movement in the cardiac calcium channel. Science 262:575-578.

Noble S, Shimoni Y (1981) The calcium and frequency dependence of the slow inward current "staircase" in frog atrium. J Physiol (Lond) 310:57-75.

Pérez-García MT, Kamp TJ, Marbán E (1995) Functional properties of cardiac L-type calcium channels transiently expressed in HEK293 cells. J Gen Physiol 105:289-306.

Pietrobon D, Hess P (1990) Novel mechanism of voltage-dependent gating in L-type calcium channels. Nature 346:651-655.

Pitler TA, Landfield PW (1990) Aging-related prolongation of calcium spike duration in rat hippocampal slice neurons. Brain Res 508:1-6.

Plummer MR, Logothetis DE, Hess P (1989) Elementary properties and pharmacological sensitivities of calcium channels in mammalian periphcral ncurons. Neuron 2:1453-1463.

Plummer MR, Rittenhouse A, Kanevsky M, Hess P (1991) Neurotransmitter modulation of calcium channels in rat sympathetic neurons. J Neurosci 11:2339-2348.

Randall A, Tsien RW (1995) Pharmacological dissection of multiple types of $\mathrm{Ca}^{2+}$ channel currents in rat cerebellar granule neurons. J Neurosci 15:2995-3012.

Regan LJ, Sah DW, Bean BP (1991) $\mathrm{Ca}^{2+}$ channels in rat central and peripheral neurons: high-threshold current resistant to dihydropyridine blockers and omega-conotoxin. Neuron 6:269-280.

Sather WA, Tanabe T, Zhang JF, Mori Y, Adams ME, Tsien RW (1993) Distinctive biophysical and pharmacological properties of class A (BI) calcium channel alpha 1 subunits. Neuron 11:291-303.
Sculptoreanu A, Rotman E, Takahashi M, Scheuer T, Catterall WA (1993a) Voltage-dependent potentiation of the activity of cardiac L-type calcium channel alpha 1 subunits due to phosphorylation by cAMP-dependent protein kinase. Proc Natl Acad Sci USA 90:10135-10139.

Sculptoreanu A, Scheuer T, Catterall WA (1993b) Voltage-dependent potentiation of $\mathrm{L}$-type $\mathrm{Ca}^{2+}$ channels due to phosphorylation by cAMPdependent protein kinase. Nature 364:240-243.

Sigworth FJ, Sine SM (1987) Data transformations for improved display and fitting of single-chamel dwell time histograms. Biophys J 52:1047-1054

Slesinger PA, Lansman JB (1991) Reopening of $\mathrm{Ca}^{2+}$ channels in mouse cerebellar neurons at resting membrane potentials during recovery from inactivation. Neuron 7:755-762.

Spruston N, Schiller Y, Stuart G, Sakmann B (1995) Activity-dependent action potential invasion and calcium influx into hippocampal CAl dendrites. Science 268:297-300.

Swandulla D, Armstrong CM (1988) Fast-deactivating calcium channels in chick sensory neurons. J Gen Physiol 92:197-218.

Thibault O, Porter NM, Landfield PW (1993) Low $\mathrm{Ba}^{2+}$ and $\mathrm{Ca}^{2+}$ induce a sustained high probability of repolarization openings of L-typc $\mathrm{Ca}^{2++}$ channels in hippocampal neurons: physiological implications. Proc Natl Acad Sci USA 90:11792-11796.

Thompson LT, Deyo RA, Disterhoft JF (1990) Nimodipine enhances spontaneous activity of hippocampal pyramidal neurons in aging rabbits at a dose that facilitates associative learning. Brain Res 535:119-130.

Westenbroek RE, Ahlijanian MK, Catterall WA (1990) Clustering of L-type $\mathrm{Ca}^{2+}$ channels at the base of major dendrites in hippocampal pyramidal neurons. Nature 347:281-284.

Wong RK, Prince DA (1978) Participation of calcium spikes during intrinsic burst firing in hippocampal neurons. Brain Res 159:385-390.

Wong RK, Prince DA (1981) Afterpotential generation in hippocampal pyramidal cells. J Neurophysiol 45:86-97.

Zygmunt AC, Maylie J (1990) Stimulation-dependent facilitation of the high threshold calcium current in guinea-pig ventricular myocytes. J Physiol (Lond) 428:653-671. 